Proceedings of the 2011 Winter Simulation Conference

S. Jain, R.R. Creasey, J. Himmelspach, K.P. White, and M. Fu, eds.

\title{
THE IMPACT OF PRODUCT VARIETY ON LOGISTICS PERFORMANCE
}

\author{
Xavier de Groote \\ Enver Yücesan \\ INSEAD \\ Technology and Operations Management Area \\ Boulevard de Constance \\ 77305 Fontainebleau, FRANCE
}

\begin{abstract}
We study the impact of product variety on the performance of a simple integrated production-distribution system equivalent to the stochastic economic lot-scheduling problem. We show that, keeping the total demand constant, the expected cost of inventories and backorders increases linearly with the number of products. This result is contrary to the conventional wisdom - based on pooling economies - whereby the expected cost would increase as the square root of the number of products. The linear relationship stems from the increase in replenishment lead time induced by an increase in product variety. In a systematic simulation study we show the phenomenon to be quite robust, as it does not depend on load, flexibility, or processing variability.
\end{abstract}

\section{INTRODUCTION}

The trend toward increasing the breadth of product lines has long been well known (Gilmore and Pine 2000). For example, in the packaged goods industry, from 1986 to 1996, the number of new product introductions has doubled from 12,000 to 24,000 (Marketing Intelligence Service 1997). Similarly, Safeway reports that the number of products available in large supermarkets has increased thirty-fold from an average of 1000 in the 1950's. One frequent argument for a broader product line is that customized products command premium prices in the market place (Fortune 1993). Examples include Levi Strauss's make-to-order jeans, personalized m\&m's, and Ingersoll-Rand's production of different prismatic parts in lot sizes of one (Goldhar and Lei 1995). Rapid technology changes and globalization (or expansion of customer base) are also cited as key drivers of product proliferation (Lee 1996). Rapid technological innovation pushes a company to sell multiple versions of the same product simultaneously. Globalization, on the other hand, imposes additional requirements on the product due to differences in language, local regulations, and technical considerations such as voltage, frequency, and plug conventions.

The breadth of the product line has also been considered as one of the key drivers of logistics performance (e.g., Magee, Copacino, and Rosenfield 1985). Thönemann and Bradley (2002) assert that high product variety impairs supply chain performance, particularly in terms of replenishment lead times and cost. They report that, for a hard drive manufacturer, the average lead time for product lines with high product variety is longer than the average lead time for product lines with low product variety. Longer average lead times, in turn, force the retailers to hold more inventory, increasing their costs. Other companies such as Procter \& Gamble and Ford have reduced the number of variants of their products in an effort to control the cost of high product variety. In spite of increasing anecdotal evidence, little analytical or empirical evidence seems to be available to confirm this conventional wisdom, let alone assess the magnitude of the impact. On the theoretical side, with a few exceptions discussed below, no systematic analysis of the phenomena relating product variety to logistics performance appears in the literature. The 


\section{De Groote and Yücesan}

impact of product variety on manufacturing costs (e.g., Banker, Datar, and Kekre 1988), on manufacturing cell performance (e.g., Kekre 1987), and on marketing (e.g., Kekre and Srinivasan 1990) has been the object of more attention.

A first answer on the impact of product variety on logistics performance is provided indirectly by Eppen (1979). In a multi-location newsvendor problem, he shows that the benefits of the centralization of safety stocks are proportional to the square root of the number of locations (in the symmetric case, where all locations have the same cost parameters and demand characteristics). The reinterpretation of this model in terms of rationalization of the product line leads to the conclusion that the cost of variety should be proportional to the square root of the number of products.

Zipkin (1995) reemphasizes that result and generalizes it. He shows that the square root effect applies to a multi-product integrated production-distribution system when the production facility is perfectly flexible (i.e., exhibits instantaneous setups).

Gupta and Srinivasan (1998) study a cyclic exhaustive production system and derive conditions under which the total work-in-process inventory actually decreases with increasing product variety. Based on these conditions, they propose control strategies to manage demand and processing rates.

In this paper, we consider a simple integrated production-distribution system with positive setup times. The proposed model is equivalent to the stochastic economic lot-scheduling problem most recently studied by Federgruen and Katalan (1996). We argue that the performance of the system deteriorates significantly as the number of products increases, keeping the total demand rate constant. In particular, the expected cost of inventory and backorder increases linearly in the number of products. The phenomenon does not depend on the load of the system, its flexibility, or the variability of processing requirements.

The significance of the result is best appreciated in light of the percentage of revenues that would typically be affected. A survey of logistics performance in Europe, by A.T. Kearney, Inc. (2004), reports that inventory and warehousing costs alone amount to 5.2 percent of revenues on average. No statistics are available on the cost of backorders and lost sales, which consist in large part of hard to evaluate opportunity costs, but their impact is likely to be significant. Suppose, for illustration purposes, that inventory and backorder costs combined amount to $10 \%$ of turnover in a particular company. The margin is $5 \%$. Our analysis suggests if the company were doubling the number of its products, these costs would increase to reach $20 \%$ of revenue. Starting with a margin of $5 \%$, such an increase in costs would bring the company to a dramatic loss situation.

A few comments are in order. First, the analysis suggests that costs would increase linearly if the design of the production and distribution system is not improved to support the increase in variety. Second, an increase in variety should typically be associated with an increase in revenues. Our analysis focuses on the cost impact only. We further assume that the total demand rate remains constant, implying that individual product demand rates decrease as variety is added. This is quite typical in highly competitive markets where new products are introduced to maintain market share rather than increasing the total market size (Berry and Cooper 1999). Third, the increase in inventory and backorder costs and the associated phenomenon of increase in replenishment lead time is not likely to be easily traceable by standard accounting systems as it would impact indirect operating costs in terms of overheads and opportunity costs.

The paper is organized as follows. Section 2 introduces the model and notation. A simple heuristic argument describing the phenomenon is offered in Section 3. Section 4, the main body of the paper, reports the results of a systematic simulation study. The paper closes in Section 5 with comments and conclusions.

\section{THE MODEL}

As illustrated in Figure 1, we consider an integrated production-distribution system with $n$ different products facing independent stochastic demand and sharing a common production facility with setups. Demand is met from inventory carried at the distribution facility; unmet demand is backordered. The transportation delay between the production and distribution facilities is assumed to be negligible (e.g., both facilities are on the same site). The problem is equivalent to the stochastic economic lot-scheduling 


\section{De Groote and Yücesan}

problem. Following a recent analysis of this model by Federgruen and Katalan (1996), we focus on cyclical exhaustive base-stock policies. Under such a policy, the production facility rotates between the different products in a fixed sequence; once initiated, the production of a particular item continues until inventory reaches a prespecified base-stock level. This operating policy, called the cyclic exhaustive polling policy in the queueing literature, is easy to implement; moreover, it minimizes the amount of unfinished work in the system.

The demand of the different products is assumed to follow a Poisson process. For simplicity, we restrict the analysis to the symmetric case in which all the products have identical demand and production parameters. Let $\lambda$ denote the aggregate demand rate. The demand rate of any particular product is then given by $\mu_{D}=\lambda / n$, while the standard deviation is given by $\sigma_{D}=\sqrt{\lambda / n}$.

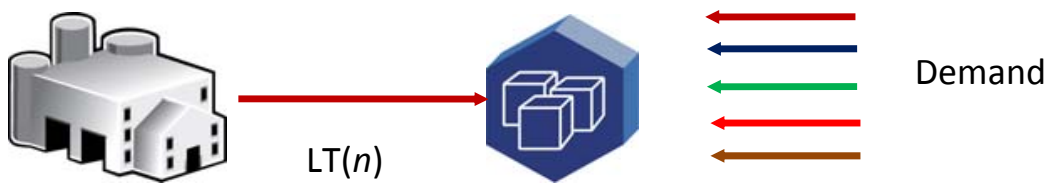

$\begin{array}{ll}\text { Production Facility: } & \text { Distribution Facility: } \\ \text { - Setup time } & \text { - Number of products } \\ \text { - Lot size } & \text { - Inventory levels } \\ \text { - Sequencing } & \text { - Backlogs }\end{array}$

Figure 1: Production-distribution system

The production facility rotates between the different products. The processing of a particular product starts with a setup of duration $r$ followed by production at a rate $\mu$ until the inventory level at the distribution facility reaches the specified base stock level $s$. (We do not consider direct setup costs; transportation is instantaneous with a transfer lot-size of one.) In the simulation study of Section 4, we consider the cases of both deterministic and stochastic processing times.

The performance of the system is evaluated in terms of the expected level of inventory, $I$, and the expected level of backorders, $B$. Let $P$ denote the (discrete) probability distribution of demand during the replenishment lead time. The sequence of orders, setups and production is not affected by changes in the base stock level. Thus, the distribution $P$ is independent of the base stock level $s$ and the expected performance of the system can be evaluated as in a newsvendor problem (Theorem 1 in Federgruen and Katalan, 1996). We then have

$$
\begin{aligned}
& I=\sum_{x=0}^{s}(s-x) P(x), \text { and } \\
& B=\sum_{x=s}^{\infty}(x-s) P(x) .
\end{aligned}
$$

In Section 4, the above relations are used to evaluate the performance of the system in a simulation study. By the above argument, it suffices to simulate the system for a particular value of the base stock, construct the distribution $P$, based on that distribution calculate the performance of the system for other values of the base stock, and finally plot the resulting tradeoff curves. (The constructed distribution can also be used to optimize the base stock level for given values of the inventory holding cost and shortage cost.)

To recap, we focus on the impact of product variety on performance, keeping the aggregate demand rate $\lambda$ constant. A possible increase in demand triggered by a broader product line is not considered here. We are rather interested in the impact of other parameters (setup time, processing rate and the resulting load factor, and variability of processing) on the relation between performance and variety. The base- 


\section{De Groote and Yücesan}

stock level does not play a direct role in the analysis as we compare tradeoff curves (i.e., we compare performance for all possible values of the base-stock level).

\section{HEURISTIC ARGUMENT}

The combination of two phenomena shapes the impact of an increase in product variety on the performance of the above system. The first phenomenon is the loss of pooling economies associated with the disaggregation of demand into smaller segments. This effect is equivalent to the decentralization of inventories in a multi-location newsvendor problem, as first analyzed by Eppen (1979). The second phenomenon is the increase in replenishment lead time associated with an increase in variety. An increase in product variety affects lot-sizing decisions and production cycles, which in turn affect lead times, as first emphasized by Karmarkar (1987).

The following heuristic argument suggests that the performance of the production-distribution system, measured in terms of inventory and backorder costs, might deteriorate linearly in the number of products. This intuitive argument is confirmed by the simulation study of section 4 .

Let $\sigma_{R}$ denote the standard deviation of the replenishment lead time demand for an individual product. If we approximate the distribution of the replenishment lead time demand by a normal distribution, the expected inventory and backorder cost is proportional to $\sigma_{R}$. Recall that $\mu_{D}$ and $\sigma_{D}$ denote the expected value and standard deviation, respectively, of the demand per unit of time for an individual product. Let $\mu_{L}$ and $\sigma_{L}$ denote the expected value and standard deviation, respectively, of the replenishment lead time. Assuming independence of $D$ and $L$ (clearly an approximation in the integrated productiondistribution system considered in section 2) we have (see Silver and Peterson 1985):

$$
\sigma_{R}=\sqrt{\mu_{L} \sigma_{D}^{2}+\mu_{D}^{2} \sigma_{L}^{2}} \text {. }
$$

As argued in section 2, $\mu_{D}$ and $\sigma_{D}^{2}$ are proportional to $1 / n$. For a fixed lead time, this yields the square root effect of Eppen (1979). The key point in the argument that follows is that a change of product variety should also affect replenishment lead times.

The effect of a change in $n$ on $\mu_{L}$ is easy to predict. Let $q$ denote the expected lot-size. The effective utilization of the production facility is given by $\lambda(r / q+1 / \mu)$. A cyclical base stock policy with no planned idle time will typically yield an effective utilization of $100 \%$. Setting the above expression to 1 and solving for $q$ yields

$$
q=\frac{\lambda r}{1-\rho},
$$

where $\rho=\lambda / \mu$ denotes the system load. On average, the replenishment lead time is approximately equal to half the duration of a production cycle. After substitution of $q$ from the above expression, this yields

$$
\mu_{L} \approx \frac{n}{2}\left(r+\frac{q}{\mu}\right)=\frac{n}{2} \frac{r}{(1-\rho)} .
$$

The effect of a change in $n$ on $\sigma_{L}$ is harder to predict intuitively. One reasonable first guess is that the coefficient of variation of $L$ would not be affected by $n$ so that $\sigma_{L}$ would increase linearly in $n$. Putting together the impact on $D$ and $L$, we conclude that $\sigma_{R}$ should not be affected by a change in $n$. In other words, the expected inventory and backorder cost associated with one particular product should remain unchanged when the number of products, $n$, is increased.

As the demand rate associated with individual products decreases with an increase in variety, the cost per unit increases linearly. Thus, we expect the aggregate performance of the system, measured as the 


\section{De Groote and Yücesan}

sum of the inventory and backorder cost of the individual products, to increase linearly in the variety of the product line. This heuristic argument is validated in the simulation study of section 4 .

\section{INTEGRATED PRODUCTION-DISTRIBUTION SYSTEMS}

\subsection{The Simulation Study}

The production-distribution system described in Section 2 is analyzed through discrete event simulation to assess the impact of product variety on logistics performance. Recall that we are considering a system with $n$ different products experiencing independent stochastic demand and sharing a common production facility with setups. Demand is met from inventory carried at the distribution facility; unmet demand is backordered. The transportation delay between the production and distribution facilities is assumed to be negligible. The production facility is modeled as a polling system (Federgruen and Katalan 1996) with cyclic exhaustive service. Under such a service policy, the production facility rotates between the different products in a fixed sequence; once initiated, the production of a particular item continues until the inventory reaches a pre-specified base-stock level. A non-zero set-up time is incurred when the facility switches to another product. Unlike Federgruen and Katalan (1996), we do not insert any idle time for the production facility.

Other variants of the service policy exist. In gated service, as opposed to exhaustive service, the server processes only those entities that were present at the instant where the server switches to a particular queue. Federgruen and Katalan (1996) observe that gated service is inferior to exhaustive service. It is also possible to follow polling tables instead of a cyclic service policy (Federgruen and Katalan 1996). This variant is especially useful for modeling asymmetric products or different priority schemes.

In the simulation study, the impact of product variety on logistics performance is investigated under varying degrees of system load (the ratio of demand rate and production rate), flexibility (measured by setup times), and variability of the production process. Demand is assumed to follow an independent Poisson stream for each product; service times are independent and exponentially distributed. Setup times are deterministic. Parameter values were selected based on the heuristic argument presented in section 3. In other words, the arrival rate, the service rate, and the set up time are set to ensure an effective system utilization that is strictly less than $100 \%$. This, in turn, guarantees the achievement of steadystate conditions in the simulation experiments.

The model is implemented in SLAMSYSTEM (Pritsker 1987). After a warm-up period of 10,000 service completions, each replication was run for 200,000 units of demand for each product under steadystate conditions. Five independently seeded replications were conducted for each scenario; common random numbers were used across scenarios to reduce estimator variance.

\subsection{Observations}

Figure 2 depicts the average replenishment lead times for 2, 4, 8, and 16 products at high, medium, and low levels of system load. We observe that the average replenishment lead time grows linearly as the number of products increases. Moreover, this growth appears to be independent of the system load. This observation is consistent with the heuristic argument that an increase in product variety affects lot sizing decisions and production cycles, which, in turn, affect lead times.

The increase in replenishment lead time is coupled with the loss of pooling economies as logistics performance deteriorates with increasing product variety. Figure 3 shows the inventory-service trade-off with the number of products varying from 2 to 16. Unlike the case with exogenous (fixed) lead times, where the aggregate cost increases as the square root of $n$, the combined effect of endogenous replenishment lead times and the loss of pooling economies results in a cost increase that is linear in $n$. As the system load gets lighter, however, the effect tends to the square root phenomenon. 


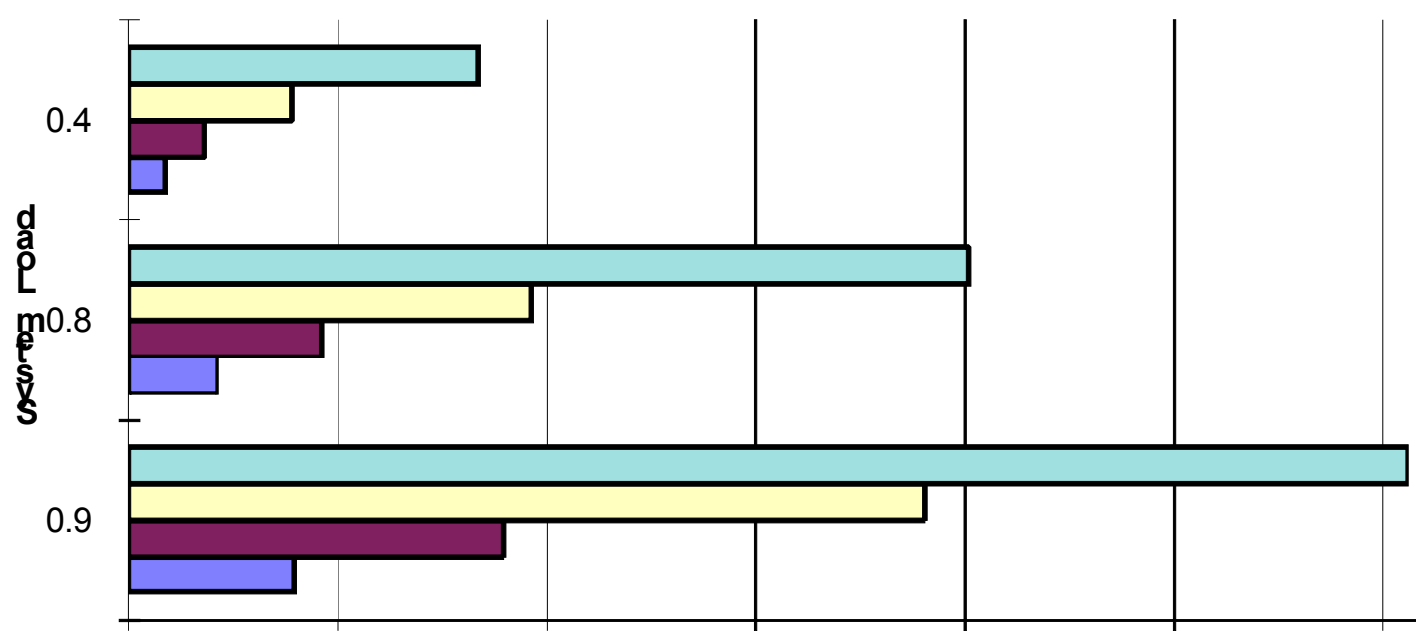

Figure 2: Replenishment lead time and product variety

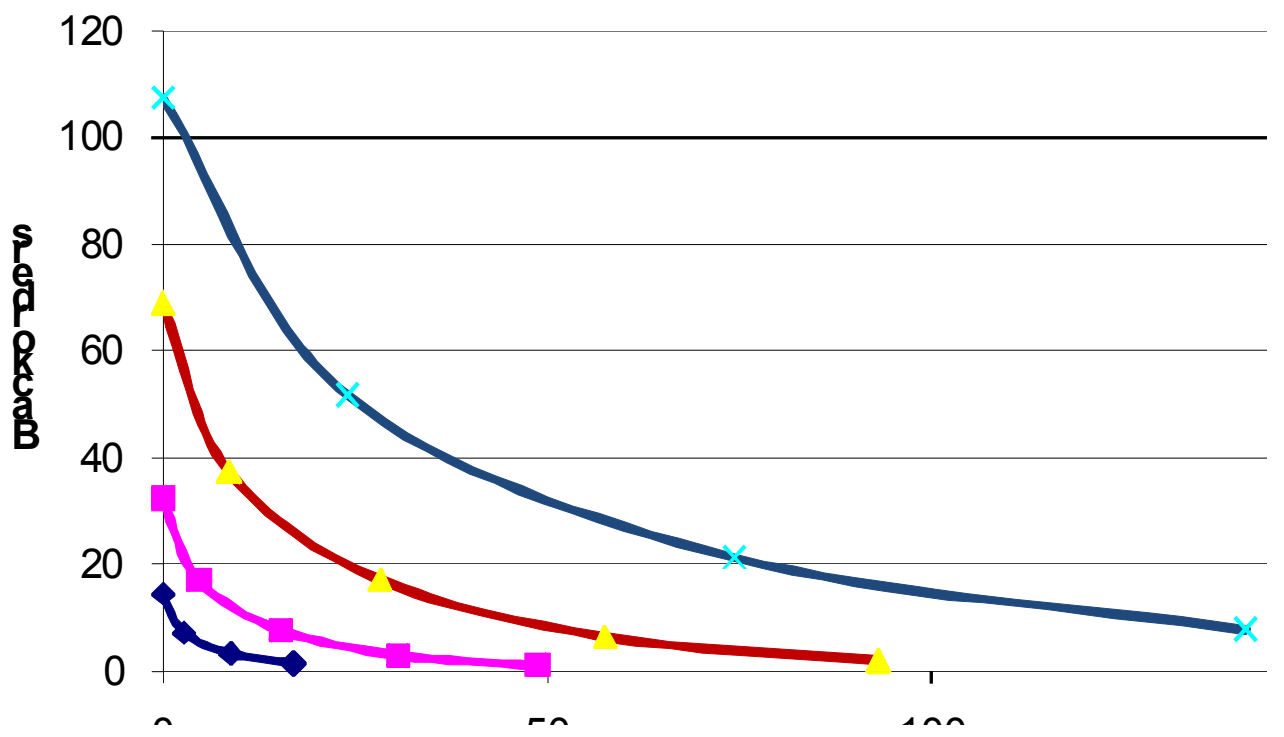

Figure 3: Inventory-service trade-off (load $=0.90)$

In addition to the linear deterioration in the first-order effects, the standard deviation of the replenishment lead time also increases linearly with the number of products, $n$. This is shown in Figure 4. Given that the standard deviation of the replenishment lead time is one of the key drivers of safety stocks, a broader product line should then result in higher expected inventory levels. We therefore conclude that both the expected lead time and its standard deviation increase linearly with the breadth of the product line. Since the former increases the cycle stock and the latter increases the safety stock, the overall inventory levels must grow at least linearly with the number of products, $n$. 


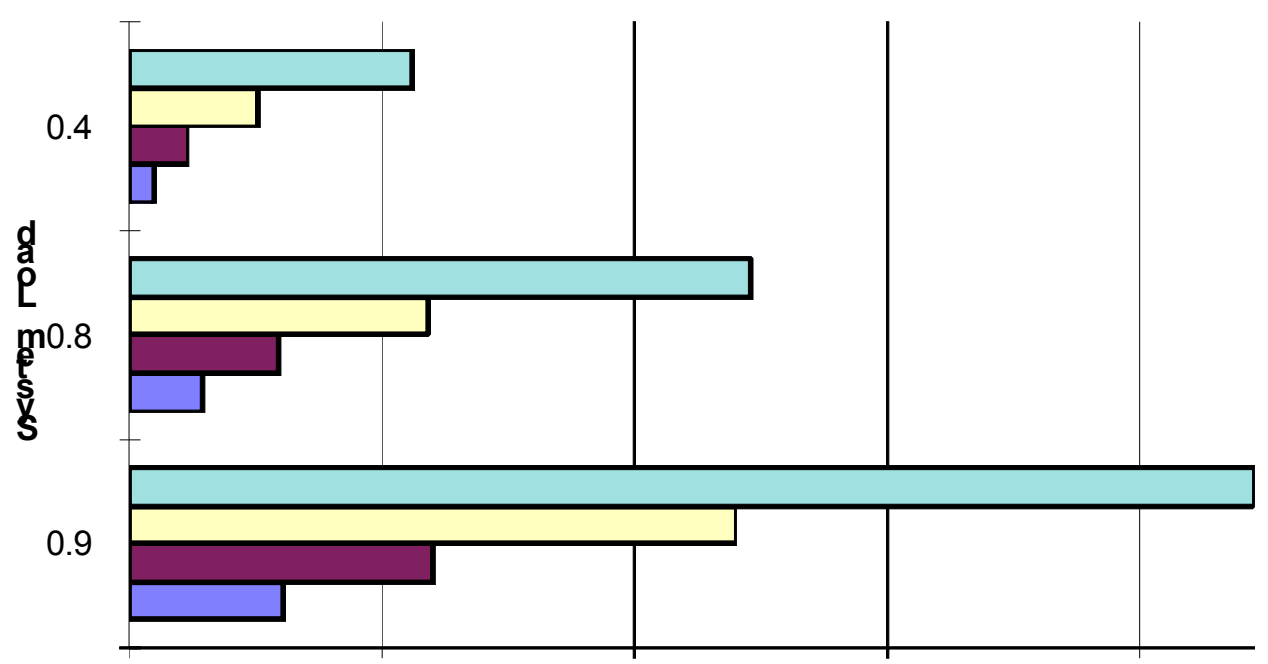

Figure 4: Standard deviation of replenishment lead time

\subsection{Sensitivity Analysis}

To assess the robustness of the observations and to understand the impact of various factors on system performance, we conducted a full factorial experiment. Table 1 lists the system parameters under investigation. They include the breadth of the product portfolio, the utilization of the system (system load), the length of the set-up time, and the volatility in the demand and manufacturing processes. The parameter values have been selected so as to ensure coverage of a wide valid experimental region. Within the $2^{5}$ factorial experiment, we replicated each design point five times; each replication was run for 200,000 units of demand for each product, following an initial warm-up period. Common random numbers were used across design points to reduce the variance of the estimators. The performance metrics of interest include expected total inventory (expressed in terms of the number of units), expected total backlog (number of units), and the expected replenishment lead time (number of time periods).

Table 1: The Factorial Experiment

\begin{tabular}{l|l|l}
\hline FACTOR & LOW LEVEL & HIGH LEVEL \\
\hline no. of products, $n$ & 4 & 16 \\
\hline system load & 0.80 & 0.90 \\
\hline setup time & 10.0 & 40.0 \\
\hline CV (demand) & 0 (deterministic) & 1 (exponential) \\
\hline CV (manufacturing) & 0 (deterministic) & 1 (exponential) \\
\hline
\end{tabular}

Tables 2 and 3 contain the results of the experiment for the main effects and two-way interactions, respectively. The responses marked with an asterisk $(*)$ represent statistically significant effects based on a $90 \%$ confidence interval for that response value. As expected, the breadth of the product line has a significant impact on both operating costs (in terms of the expected total inventory) and customer service (in terms of expected total backlogs and the replenishment lead time). An increase in system load leads to a decrease in expected total inventories as the production facility falls behind in meeting customer orders, a phenomenon indicated by an increase in both expected total backlogs and expected replenishment lead times. An increase in setup times or in the variability of the manufacturing process has a similar impact on system performance. Bradley and Conway (1998) offer a crisp description of this phenomenon. 


\section{De Groote and Yücesan}

Table 2: Main effects: impact on inventory, backlog, and lead time

\begin{tabular}{l|l|l|l|l|l}
\hline & \#Products, $\boldsymbol{n}$ & Load & Setup & CVdmd & CVmfg \\
\hline Inventory & $37.72^{*}$ & $-14.65^{*}$ & $-36.79^{*}$ & 0.71 & -3.74 \\
\hline Backlog & $108.56^{*}$ & $77.78^{*}$ & $153.40^{*}$ & $3.45^{*}$ & $20.79^{*}$ \\
\hline Lead Time & $1016.07^{*}$ & $464.32^{*}$ & $956.32^{*}$ & $13.46^{*}$ & $122.67^{*}$ \\
\hline
\end{tabular}

Table 3: Two-way interactions between no. of products and other system characteristics

\begin{tabular}{l|l|l|l|l}
\hline$n \times$ & Load & Setup & CVdmd & CVmfg \\
\hline Inventory & $-7.55^{*}$ & $-22.19^{*}$ & 0.83 & -3.19 \\
\hline Backlog & $45.17^{*}$ & $97.99^{*}$ & 0.56 & $18.22^{*}$ \\
\hline Lead Time & $265.93^{*}$ & $605.68^{*}$ & -1.21 & $105.08^{*}$ \\
\hline
\end{tabular}

From the two-way interactions, namely the interactions between the breadth of the product portfolio and other system characteristics such as system load, set up times, and the variability in demand and supply, we further observe that a broad product line coupled with an increase in system load or in setup times or in the variability of the manufacturing process leads to increased operating costs and poorer service. It is also observed that the breadth of the product line and the variability of the demand process have no significant combined effect on system performance.

\section{CONCLUSIONS}

Product proliferation creates a major operational challenge in manufacturing. In this paper, we have captured some essential drivers of the impact of product variety on logistics performance through a simple model of an integrated production-distribution system. In particular, we have established that, keeping total demand constant, the expected cost of inventories and backorders increases linearly with the number of products due to the loss of pooling economies. Furthermore, the phenomenon appears to be quite robust, as it does not depend on load, flexibility, or processing variability. Our results therefore quantitatively support earlier intuition on the operational challenges of product proliferation (Miller and Vollman 1985).

In addition, a preliminary analysis of the data collected though the Best Factory Award (an initiative undertaken by several European business schools and business magazines) has indicated that our results are indeed valid (Loch et al. 2003). Despite the low R-square, which can be explained by the multitude of variables affecting inventory performance, the direction of the empirical findings support the linearity result demonstrated by the simulation, especially in the case of high setup times, a surrogate metric for low flexibility.

In practice, there have been several initiatives to better manage the operational challenge created by product proliferation. Companies have invested in information technology to enhance the transparency of supply chains and to reduce the order fulfillment cycle. Other initiatives include the redesign of products (e.g., promoting part commonality, component standardization) and/or the restructuring of the manufacturing process (e.g., postponement, modular design) to mitigate the inventory-service trade-off. From a unifying perspective, these initiatives are all instances of risk pooling, the use of a pool of resources to satisfy several classes of demands. More broadly, risk pooling includes strategies such as centralization of inventory (Eppen 1979), transshipments (Herer, Tzur, and Yücesan 2006), delayed differentiation (Lee and Tang 1997), component commonality (Gerchak, Magazine, and Gamble 1988), product substitution (Parlar and Goyal 1984), and flexible capacity (van Mieghem 1998).

The current study focuses exclusively on cost. However, an increase in product variety should hopefully be associated with an increase in revenues. There exists some empirical evidence suggesting that the increase in manufacturing costs due to higher product variety is outpaced by an increase in revenues, yielding higher profitability (Kekre and Srinivasan 1990). An integrated production- 


\section{De Groote and Yücesan}

distribution model with explicit cost and revenue components should shed further light on this important interaction.

\section{ACKNOWLEDGMENTS}

This paper celebrates the memory of my colleague, Xavier de Groote, who left us immaturely fifteen years ago, leaving behind a huge void both professionally and personally.

\section{REFERENCES}

A.T. Kearney, Inc. 2004. Logistics Performance in Europe. Company study report. Accessed July 23, 2011. http://www.elalog.org/publications/atkearney2004.html.

Banker, R. D., S. M. Datar, and S. Kekre. 1988. "Relevant Costs, Congestion and Stochasticity in Production Environments." Journal of Accounting \& Economics 10:1-27.

Berry, W. L., and M. C. Cooper. 1999. "Manufacturing Flexibility: Methods for Measuring the Impact of Product Variety on Performance in Process Industries." Journal of Operations Management 17:163178.

Bradley, J. R., and R. W. Conway. 1998. "Lot Sizes and Cyclic Inventories." Working paper. Johnson Graduate School of Management, Cornell University. Ithaca, NY. Accessed July 23, 2011. http://onlinelibrary.wiley.com/doi/10.1111/j.1937-5956.2003.tb00215.x/abstract.

Eppen, G.D. 1979. "Effects of Centralization on Expected Costs in Multi-location Newsboy Problem." Management Science 25:498-501.

Federgruen, A., and Z. Katalan. 1996. "The Stochastic Economic Lot Scheduling Problem: Cyclical Basestock Policies with Idle Times.” Management Science 42:783-796.

Fortune. 1993. "Meet the New Consumer." Fortune Magazine, 22 October 1993, 90-93.

Gerchak, Y., M. J. Magazine, and A. B. Gamble. 1988. "Component Commonality with Service Level Requirements." Management Science 34:753-760.

Gilmore, J. H., and B. J. Pine II. 2000. Markets of One. Boston, MA: Harvard Business School Press.

Goldhar, J. D., and D. Lei. 1995. "Variety is Free: Manufacturing in the Twenty-First Century." Academy of Management Executive 9: 73-77.

Gupta, D., and M. S. Srinivasan. 1998. "How does Product Proliferation Affect Responsiveness?" Management Science 44:1017-1020.

Herer, Y. T., M. Tzur, and E. Yücesan. 2006. "The Multi-Location Transshipment Problem." IIE Transactions 38:185-200.

Karmarkar, U. S. 1987. "Lot-Sizes, Lead Times and In-Process Inventories," Management Science 33:409-423.

Kekre, S. 1987. "Performance of a Manufacturing Cell with Increased Product Mix." IIE Transactions 19:329-339.

Kekre, S., and K. Srinivasan. 1990. "Broader Product Line: a Necessity to Achieve Success?" Management Science 36:1216-1231.

Lee, H. 1996. "Effective Inventory and Service Management through Product and Process Redesign." Operations Research 44:151-159.

Lee, H., and C. Tang. 1997. "Modeling the Costs and Benefits of Delayed Product Differentiation." Management Science 43:40-53.

Loch, C., L. Van der Heyden, L. Van Wassenhove, A. Huchzermeier, and C. Escalle. 2003. Industrial Excellence: Management Quality in Manufacturing. Berlin: Springer.

Magee, J. F., W. C. Copacino, and D. B. Rosenfield. 1985. Modern Logistics Management: Integrating Marketing, Manufacturing, and Physical Distribution. New York, N.Y.: Wiley.

Marketing Intelligence Service. 1997. "Unlock Product Launch Trends with Product Launch Analytics." Accessed July 23, 2011. http://www.productscan.com. 
Miller, J. G., and T. E. Vollman. 1985. "The Hidden Factory." Harvard Business Review 63: 142-150.

Parlar, M., and S. Goyal. 1984. "Optimal Ordering Decisions for Two Substitutable Products with Stochastic Demands." OPSEARCH 21:1-15.

Pritsker, A. A. B. 1987. Introduction to Simulation and SLAM II. New York: Wiley.

Silver, E. A., and R. Peterson. 1985. Decision Systems for Inventory Management and Production Planning. New York: John Wiley \& Sons.

Thönemann, U.W., and J.R. Bradley. 2002. "The Effect of Product Variety on Supply Chain Performance." European Journal of Operational Research 143:548-569.

van Mieghem, J. A. 1998. "Investment Strategies for Flexible Resources," Management Science 44:10711078.

Zipkin, P. H. 1995. "Performance Analysis of a Multi-item Production-Inventory System under Alternative Policies," Management Science 41:690-703.

\section{AUTHOR BIOGRAPHIES}

XAVIER DE GROOTE was a Professor of Operations Management in Technology and Operations Management Area at INSEAD in Fontainebleau, France. He earned a PhD degree from the Graduate School of Business at Stanford University. Prior to joining INSEAD, he served on the faculty of the Wharton School at the University of Pennsylvania.

ENVER YÜCESAN is a Professor of Operations Management in Technology and Operations Management Area at INSEAD in Fontainebleau, France. His work focuses on raking and selection in simulation as well as modeling and analysis applications in supply chain management. He holds a PhD in Operations Research from Cornell University. He has an undergraduate degree in Industrial Engineering from Purdue University. He has proudly served as the Program Chair at WSC'10. His e-mail is enver.yucesan@insead.edu. 